\title{
Outcome of children with community acquired pneumonia treated with injection crystalline penicillin a prospective study
}

\author{
K Udaya ${ }^{1}$, Murteli V.K.B ${ }^{2}$ \\ ${ }^{1}$ Dr Udaya K, Senior Resident, Department of Paediatrics, Koppal Institute of Medical Sciences, Koppal, Karnataka, \\ ${ }^{2}$ Dr Vijaykumar B. Murteli, Assistant Professor, Department of Paediatrics, Belagavi Institute of Medical Sciences, \\ Belagavi, Karnataka, India.
}

Address for Correspondence: Dr Udaya K, Senior Resident, Department of Paediatrics, Koppal Institute of Medical Sciences, Koppal, Karnataka, India, Email-uday.bmc@gmail.com

\begin{abstract}
Objective: To study the outcome of children hospitalized with community acquired pneumonia treated with aqueous penicillin G. Design: Prospective study. Setting: The study was conducted in Belagavi Institute of Medical Sciences, a referral hospital during 2014-2015. Children aged from more than 2 months to 18 yrs of age were studied. Total of 84 children who met the inclusion criteria were studied. Eligible children were given injection crystalline penicillin 2 lakh $\mathrm{IU} / \mathrm{kg}$ in four divided doses after drug sensitivity testing. Children were assessed every $12^{\text {th }}$ hourly, for respiratory rate, pulse rate, blood pressure and signs of respiratory distress. In case of worsening of symptoms, persistence of tachynpea, fever, till 48 hours, antibiotic was changed. The study was conducted to know the proportion of children with community acquired pneumonia who responded to crystalline penicillin injection. Results: Out of 84 children treated with crystalline penicillin 79 responded, antibiotic was changed for the other 5 children. 3 boys out of 48 and 2 girls out of 36 did not respond to crystalline penicillin. 2 out of 24 children in the age group of 2-12 months, 3 out of 33 in the 1-5 yrs, did not respond to crystalline penicillin. Persistence of tachypnea at the end of 48 hours was the indication for change of change of antibiotics in 5 children. No adverse outcome was noted. The mean duration of stay in the hospital among the studied children was 7 days $(6.93 \pm 1.28)$. Conclusion: Injection crystalline penicillin effectively cures and is apt to be used as a first line antibiotic in treating hospitalized children with community acquired pneumonia.
\end{abstract}

Keywords: Respiratory infection, antimicrobial resistance, pneumococci.

\section{Introduction}

Acute respiratory infection is one of the leading causes of morbidity and mortality in children under 5 years of age in developing countries, and is responsible for an estimated 1.2 million deaths worldwide in this age group every year [1]. There is increasing concern about the problem of antimicrobial resistance which is related to the amount of antibiotics used [2]. Since Streptococcus pneumoniae is the major cause of CAP in developing countries and in India, pneumococci have a very low incidence $(1.3 \%)$ of resistance to penicillin [3], it can be used as the first line antibiotic in CAP. Other beta lactam antibiotics like third generation cephalosporins are empirically being used in developing country like India, as recommended by different medical society $[4,5]$. However, there are limited

Manuscript received: $24^{\text {th }}$ July 2016

Reviewed: $4^{\text {th }}$ August 2016

Author Corrected; $14^{\text {th }}$ August 2016

Accepted for Publication: $28^{\text {th }}$ August 2016 studies done in recent past in India to know the relevance of using basic antibiotic like crystalline penicillin in treatment of CAP in the present era of antibiotic resistance. Hence this study has been proposed to know the outcome of children hospitalized with community acquired pneumonia treated with aqueous penicillin $\mathrm{G}$.

\section{Methodology}

This was a prospective study done on children admitted with community acquired pneumonia at Belagavi Institute of Medical Sciences, Belagavi, Karnataka a teaching hospital. The patient population comprises, mainly of low income group from rural areas, urban slums, referred patients from surrounding rural areas, private clinics. This study was undertaken during December 2013 to March 2015. Children aged more 
than 2 months to $18 \mathrm{yrs}$ of age were studied, who met the inclusion criteria of fever and cough for duration of less than 14 days with any one of the following like, tachypnea, chest indrawing, poor feeding, no response to appropriate oral antibiotics, toxic appearance, any of the auscultatory findings like, crepitation/bronchial breath sounds/reduced breath sounds, radiologically proven pneumonia- pulmonary infiltrates, as in case of mild or moderate disease, the radiographical difference between bacterial and viral causes of pneumonia does not exist [6].

Children with chronic lung disease, human immunodeficiency virus infection, underlying cardiac diseases, bronchial asthma, those with previous enrolment in study and children with documented evidence of intravenous antibiotics administration for more than 24 hours were excluded.

The purpose of the study was explained and written consent was obtained from the parents of the children before enrolling into study. A predesigned proforma was used to collect information regarding age, sex, socio demographic profile, presenting complaints like duration of fever, cough, hurried breathing, chest indrawing, and decreased feeding, lethargy and convulsions.

Relevant past and family history were also taken. Birth history which included term/preterm, birth weight was documented. Eligible children were given injection crystalline penicillin 2 lakh IU/kg in four divided doses after drug sensitivity testing. Children were assessed every $12^{\text {th }}$ hourly, for respiratory rate, pulse rate, blood pressure and signs of respiratory distress. In case the child deteriorates, or if tachynpea or fever persists for more than 48 hours, antibiotic was changed.

Complete general physical examination, systemic examination with special orientation towards respiratory system like Respiratory Rate, $\mathrm{SpO}_{2}$, capillary refilling time, chest indrawing, stridor, grunting, crepitations, rhonchi were noted. Routine and relevant investigations such as Hemoglobin \%, Total leukocyte count, Erythrocyte sedimentation rate, blood culture and chest X-ray were done. Any adverse effect after drug administration was noted.

\section{Results}

Total of 84 children were studied, 48 boys and 36 girls. There were 24 children in the age group of 2-24 months, 33 in 1 to 5 years and 22 children aged between 5 and 18 years. Maximum number of children was in low socioeconomic group (43 in upper lower and 37 in lower group) according to modified kuppuswamy classification. Passive smoking was present in $40.5 \%$ of studied and overcrowding was seen in $51 \%$ of children studied. $44 \%$ children were breastfed for less than six months.

\begin{tabular}{|c|c|c|c|}
\hline & Responders & Non responders & Percentage \\
\hline $2-12$ MONTH & 24 & 2 & 7.69 \\
\hline $1-5$ YRS & 33 & 3 & 8.33 \\
\hline >5 YRS & 22 & 0 & 0 \\
\hline TOTAL & 79 & 5 & 5.95 \\
\hline
\end{tabular}

Majority of them (77.6\%) presented within 4 days of onset of fever and cough, and most of them (96.5\%) by $5^{\text {th }}$ day. Out of 84 children treated with crystalline penicillin 79 responded (92.94\%), antibiotic was changed for rest 5 children 3 boys out of 48 and 2 girls out of 36 did not respond to crystalline penicillin. 2 out of 24 children in the age group of 2-12 months, and 3 out of 33 in the 1-5 years group did not respond to crystalline penicillin. Persistence of tachypnea at the end of 48 hours was the indication for change of antibiotics in 5 children along with persistence of fever in one child.

\section{Discussion}

In India, the incidence of pneumonia is estimated to be 44 million, where as 7 million in Pakistan and 6 million Bangladesh [7]. Cough and fever were the most common presenting clinical features of pneumonia in our study. Fever and cough followed by rapid or difficulty in breathing were the most common presenting complaints in a similar study done in
Himachal Pradesh, India [8]. The combination of tachypnea, tachycardia, fever, and localized findings (rales or wheezing) both before and after bronchodilator therapy identified pneumonia in $95 \%$ of children $>1$ year of age with the first episode of wheezing [9]. Similarly, the most common presenting complaints of pneumonia were cough $(99.2 \%)$, fever $(97.2 \%)$ and 
difficulty in breathing $(56.5 \%)$ in a study done in 154 hospitalized children aged more than two months with CAP, the examination findings were tachypnea (75.2\%), fever (49.7\%) and crackles (33.8\%) [10].

All these show that fever, cough and tachypnea can be used as the diagnostic tool for pneumonia where chest X-ray is not always possible, especially in rural and under equipped health settings. Since most of the causative agents of childhood pneumonia cannot be detected, antibiotic treatment is most often empiric, especially in underdeveloped countries. Various antibiotics are being used in the treatment protocol of CAP worldwide [11,12] and also in India. In our study, the data showed that CP successfully treated the great majority $(94.04 \%)$ of the children aged between 2 months to $18 \mathrm{yrs}$ with CAP.

These results are also similar to the study, where Penicillin G successfully treated 82\% (126/154) of the study group and the improvement was markedly seen on the first day of treatment itself in the retrospective cohort study done in hospitalized children with CAP in Brazil 10]. Similarly, out of 153 children hospitalized for uncomplicated CAP in Finland, 66\% were treated with penicillin $\mathrm{G}$ and they also showed a rapid and uneventful recovery [13]. Penicillin $G$ is still considered a drug of choice in hospitalized children with CAP even in many European countries with low penicillin resistance of pneumococci $[14,15,16]$. Penicillin $G$ is no longer recommended in the United States as the choice drug because of limited supply and the increasing resistance of pneumococci to penicillin, [17] whereas in western countries like Finland, 95\% of pneumococcal strains still remained sensitive to penicillin [18]. Since a majority of children with CAP responded significantly well to $\mathrm{CP}$ in our study, it could still be considered a drug of choice in hospitalized children with CAP in low income and resource poor countries like India.

\section{Conclusions}

Crystalline Penicillin is a very good drug for the treatment of CAP and can still be used as the first drug in the treatment of children with CAP. The most common clinical features like cough, fever, tachypnoea and lower chest indrawing can be used in the diagnosis of CAP where chest X-ray facilities are absent. This study however had limitation, as sample size was relatively small.
Funding: Nil, Conflict of interest: Nil

Permission from IRB: Yes

\section{References}

1. Levels and Trends in Child Mortality: Report 2012, UNICEF, New York, 2012.

2. Goossens H, Sprenger MJ. Community acquired infections and bacterial resistance. BMJ. 1998 Sep 5; 317(7159):654-7.

3. Mehta PN. Choosing antibiotics for community acquired pneumonia. Indian Pediatr. 2003 Oct; 40 (10):958-64

4. Jadavji T, Law B, Lebel MH, Kennedy WA, Gold R, Wang EE. A practical guide for the diagnosis and treatment of pediatric pneumonia. CMAJ. 1997 Mar 1; 156 (5):S703-11.

5. British Thoracic Society Standards of Care Committee. British Thoracic Society Guidelines for the Management of Community Acquired Pneumonia in Childhood. Thorax. 2002 May;57 Suppl 1:i1-24.

6. Esposito S, Principi N. Unsolved problems in the approach to pediatric community-acquired pneumonia. Curr Opin Infect Dis. 2012 Jun;25(3):286-91. doi: 10. 1097/QCO.0b013e328352b60c.

7. WORLD Health Organization. Pneumonia: The forgotten killer of children. The United Nations Children's Fund /World Health Organization; Sept 2006.

8. Bharti B, Bharti S, Verma V. Role of Acute Illness Observation Scale (AIOS) in managing severe childhood pneumonia. Indian J Pediatr. 2007 Jan; 74 (1):27-32.

9. Gershel JC, Goldman HS, Stein RE, Shelov SP, Ziprkowski M. The usefulness of chest radiographs in first asthma attacks. N Engl J Med. 1983 Aug 11; 309(6):336-9.

10. Raquel Simbalista,MarceloArau' jo,Cristiana M. Nascimento-Carvalho. Outcome of children hospitalized with community-acquired pneumonia treated with aqueous penicillin G. CLINICS 2011; 66 (1):95-100.

11. Jadavji T, Law B, Lebel MH, Kennedy WA, Gold R, Wang EE. A practical guide for the diagnosis and treatment of pediatric pneumonia. CMAJ. 1997 Mar 1;156(5):S703-11. 
12. British Thoracic Society of Standards of Care Committee. BTS guideline for the management of community acquired pneumonia in children.Thorax. 2002; 57:i1-24.

13. Juvén $\mathrm{T}$, Mertsola $\mathrm{J}$, Waris $\mathrm{M}$, Leinonen $\mathrm{M}$, Ruuskanen O. Clinical response to antibiotic therapy for community-acquired pneumonia. Eur J Pediatr. 2004 Mar; 163(3):140-4. Epub 2004 Jan 31.

14. Hedlund J, Ortqvist A, Ahlqvist T, Augustinsson A, Beckman H, Blanck C, Burman LA, Claesson B, Qvarfordt I, Elbel E, Erntell M, Follin P, Goscinski G, Holmberg H, Höfer M, Jorup C, Lidman C, Lindhusen E, Rensfeldt G, Rosenkvist E, Stenlund G, Stålberg A, Verngren K, Vig I, Wendahl S; Swedish Infectious Diseases Society Pneumonia Study Group. Management of patients with community-acquired pneumonia treated in hospital in Sweden. Scand J Infect Dis. 2002;34(12):887-92.
15. Moroney JF, Fiore AE, Harrison LH, Patterson JE, Farley MM, Jorgensen $\mathrm{JH}$ et al. Clinical outcomes of bacteremic pneumococcal pneumonia in the era of antibiotic resistance. Clin Infect Dis 2001;33:797-805.

16. Ruuskanen O, Mertsola J. Childhood communityacquired pneumonia. Semin Respir Infect. 1999 Jun; 14(2):163-72.

17. Nelson JD. Community-acquired pneumonia in children: guidelines for treatment. Pediatr Infect Dis J. 2000 Mar;19(3):251-3.

18. Pihlajamäki M, Kotilainen P, Kaurila T, Klaukka T, Palva E, Huovinen P; Finnish Study Group for Antimicrobial Resistance (FiRe-Network). Macrolideresistant Streptococcus pneumoniae and use of antimicrobial agents. Clin Infect Dis. 2001 Aug 15;33 (4):483-8. Epub 2001 Jul 20.

\section{How to cite this article?}

K Udaya, Murteli V.K.B. Outcome of children with community acquired pneumonia treated with injection crystalline penicillin a prospective study. Int J Pediatr Res.2016;3(9):657-660.doi:10.17511/ijpr.2016.i09.05. 